uninhabitable for many years; yet the AEC proposes to have as many as 2,000 of them in operation by the year 2020 in the United States alone. This would require daily 100 railway cars loaded with casks of spent fuel to be taken to no known place of safety for storage for something like half-a-million years; yet containers so far tried for such radioactive wastes have leaked in less than 40 years! From a sober biological viewpoint the entire prospect looks too appallingly dangerous even to contemplate. Clearly the world has got to develop saner means of getting energy and also to use its remaining stores of fossil fuels far less profligately.

N. P.

\title{
Whither Ecologists?
}

As they seem disinclined to control themselves in most countries, the real ecologists of the world may need to be united into an organization that would insist on, and maintain, adequately high standards of training, practice, and integrity, for its elected members. The supervising body might well be the International Association for Ecology (INTECOL), which is holding the First International Congress of Ecology at The Hague during 8-14 September 1974, when it is much to be hoped that something will be done towards remedying the present unsatisfactory situation. Indeed if nobody else raises the issue on that occasion we propose to do so ourselves.

The present situation is one of near-anarchy, in which anybody, anywhere, can call himself or herself an ecologist and even set up as an expert or consultant dealing with environmental matters often of the gravest nature. The outcome of such irresponsibility can be extremely dangerous, as for example when concerned with such hair-rising possibilities as those resulting from nuclear fission power development in the manner outlined in the preceding note. Think of the possible outcome of action based on the wrong advice given to a political leader in a situation of extreme stress: the result could be the ecodisaster of all time-for which we are waiting, but not knowing what form it will take or when or where it will strike! Whether or not an action is based on ecological principles, these should certainly be considered in any decision involving the environment-as an everincreasing proportion of outcomes nowadays seem to be. Indeed with human population pressures on space and resources building up ever more drastically, the remaining environmental options must come under increasingly severe scrutiny.

For such purposes and many others there is a vital need of really qualified ecologists of suitable training, experience, and integrity-professionals in the best sense of that most meaningful word. Thus the time seems overdue for the real ecologists of the world to get together and insist on proper standards, both among themselves and for others aspiring to join their ranks. At present the situation is wide open to all manner of charlatanism, with so many unqualified people calling themselves ecologists nowadays that the genuine ones often hesitate to do so. As we commented already in our old journal in 1972 (Biological Conservation, Vol. 4, No. 5, p. 321 ), ‘. . how would we all react if physicians and surgeons were allowed to emerge in such a haphazard manner, and to practise upon us without proper training and experience!'

Yet the biosphere is infinitely more complex than the human body, and its ills are pathetically manifold in the contexts of fragility and increasing attack. Its guardians, the ecologists, to be effective as they have to be in future, need a training which should be at least as arduous as, and should be even more widely based than, that required for medical practice. They must have adequate practical experience before pronouncing, and must do so only with absolute integrity both professionally and ethically. Moreover they should command at least comparable recognition and remuneration to that enjoyed by exponents of the most revered of other professions.

To be fully qualified an ecologist should have at least some background knowledge of a very wide range of sciences-including Botany and Zoology, Geology and Pedology, Physics and Chemistry, Oceanography and Limnology, Meteorology, Statistics, and yet some others. Thus our genuine ecologist must be highly interdisciplinary in training and outlook, while leading universities might with wide advantage provide encouragement by offering suitable degrees etc. in the field. With or without specialist emphasis to stress particular lines of interest or future specialization, this gamut of knowledge should be acquired over at least several years of intensive $a d$ hoc study and be supplemented by practical experience. Could not INTECOL, either itself or through the pertinent national or other organizations, insist on adequate standards of qualifications based on both controlled training and tested experience? Then only individuals accepted at least by their national or major regional chapter or affiliated organization should be allowed to seek employment and make pronouncements as real ecologists.

For the health and future of Man's and Nature's entire environment it would seem vitally important that suitably qualified and experienced ecologists should have due influence in the higher echelons of government and industry from now on. And, ecology being the study of living organisms in relation to their environment (including one another), it is essential that these ecologists be biologically versed.

N. P. 